\title{
A CARNAVALIZAÇÃO DO ENSINO JURÍDICO COMO FUGA DE UM HABITUS PINGUINIZADO
}

Maria Sueli R.de Sousa ${ }^{1}$ Pablo Cavalcante Costa ${ }^{2}$

THE CARNIVALIZATION OF LAW EDUCATION AS

THE ESCAPE OF A PINGUINIZED HABITUS

RESUMO: O presente texto traz o ensino jurídico com Warat por meio da categoria habitus de Bourdieu correlacionada com a formação de práticas especificas do ensino jurídico reproduzidas em um processo que ele chama de "pinguinização". A problemática é: como a carnavalização do ensino jurídico, proposto por Warat pode ajudar na modificação do habitus jurídico presente no campo do ensino do direito? Ao analisar o processo de pinguinização, há de se perceber que as práticas reproduzidas no interior do campo jurídico tendem a transformar operadores do direito em pinguins, comprometidos com valores distantes da realidade social, e acomodados na ordem dominante. A saída indicada por Warat seria a carnavalização do ensino jurídico com vistas a desfazer as representações ideológicas e explodir às avessas as ordens totalitárias que permeiam este campo.

Palavras-chave: Habitus. Campo. Direito. Pinguinização.
ABSTRACT: The present text brings legal education with Warat through Bourdieu's habitus category correlated with the formation of specific legal teaching practices reproduced in a process he calls "pinguinization". The problem is: how can the carnivalization of legal education, proposed by Warat, help to modify the legal habitus present in the field of law education? When analyzing the pinguinization process, one must realize that the practices reproduced within the legal field tend to transform legal operators into penguins, committed to values that are distant from social reality, and accommodated in the dominant order. The solution indicated by Warat would be the carnivalization of legal education in order to undo ideological representations and explode the totalitarian orders that permeate this field inside out.

Keywords: Habitus. Field. Law. Pinguinization.

\footnotetext{
${ }^{1}$ Doutora em Direito, Estado e Constituição pela Universidade de Brasília (2009), com estágio pós doutoral pelo PNPD - Programa Nacional de Pós Doutorado, na Universidade Federal Rural do Rio de Janeiro, junto ao Programa de PósGraduação em Educação, Contextos Contemporâneos e Demandas Populares (PPGEduc). Professora Associada da Universidade Federal do Piauí, Departamento de Ciências Jurídicas - DCJ. Leciona no Programa de Pós-Graduação em Sociologia, no Programa de Pós Graduação em Gestão Pública. Pesquisadora do Núcleo de Pesquisa sobre Africanidades e Afrodescendência - IFARADÁ e do grupo de pesquisa direitos humanos e cidadania - DiHuCi.

${ }^{2}$ Mestre pelo Programa de Pós-Graduação em Sociologia (PPGS) da Universidade Federal do Piauí (UFPI). Técnico em Administração pelo Instituto Federal do Piauí (IFPI). Professor Universitário e advogado.
} 


\section{INTRODUÇÃO}

O presente texto tematiza o ensino jurídico e suas práticas que reproduzem as relações de poder existentes. A questão apresentada neste artigo surge da seguinte indagação: como a carnavalização do ensino jurídico, proposto por Luis Alberto Warat pode ajudar na modificação do habitus jurídico presente no campo do ensino do direito?

Para tanto, a fim de desenvolver essa questão o texto seguira discutindo primeiramente a noção de habitus que permeia os estudos dos sociólogos Pierre Bourdieu e Nobert Elias. Em seguida, a fim de buscar caracterizar as práticas reproduzidas nos espaços forenses, buscar-se-á caracterizar as práxis desses espaços enquanto possuidores de um habitus específico que é estruturado e estruturante desses espaços. Ao final, após o diagnóstico dado pela análise da categoria habitus a partir de Bourdieu e Elias em relação ao campo jurídico, será apresentado uma alternativa para a desconstrução das práticas desses espaços através da pedagogia waratiana que acredita na carnavalização como meio criativo de subverter a ordem e repensar o ensino jurídico, podendo ser com isso uma possibilidade de repensar o habitus desses espaços.

\section{SOBRE A CONCEPÇÃO DE HABITUS}

Para além da tríade clássica de autores (Durkheim, Weber e Marx) que consolidaram a sociologia enquanto ciência, o século XX trouxe uma série de contribuições teóricas que evidencia novos conceitos, mas que também trabalha e discute conceitos já dados por outros intelectuais no passado.

Conforme Altmann (2005) há de se afirmar com propriedade que a sociologia sempre foi marcada por dualidades, as quais se caracterizam com evidências fortes de que há situações em que dois ou mais teóricos discutem a mesma temática, contudo, sobre perspectivas diferentes. Um exemplo dessa situação se dá com o habitus, uma categoria discutida tanto por sociólogos como por historiadores, linguistas e outros teóricos de áreas distintas desde há muito tempo, como: Aristóteles, Durkheim, Weber, Panofsky, Chomsky, Elias, Bourdieu dentre outros. 
Segundo Dubar (2005) a concepção de habitus tem raiz na palavra grega hexis, estando associada à ideia de que as ações humanas ultrapassariam as intenções conscientes, sendo como pensou Aristóteles "disposições adquiridas do corpo e da alma" (DUBAR, 2005, p. 77).

Todavia, já no século XIII o conceito de hexis fora introduzida na reflexão filosófica pelo teólogo italiano São Tomás de Aquino em sua obra Summa Theologiae, que traduziu a categoria para o latim, tendo então aparecido de fato à expressão habitus (modo particípio do verbo habere, cujo sentido literal estaria ligado a ter ou possuir) onde naquele contexto assumiu o sentido de "disposição durável suspensa", a qual estaria situada entre a "potência" e a "ação propositada" (WACQUANT, 2007).

O termo também fora utilizado de maneira pouco expressiva e de forma descritiva por autores clássicos da sociologia como Emilé Durkheim em seu estudo sobre a evolução pedagógica na França como aponta Wacquant (2007).

Porém, segundo Casanova (1995), é com Marcel Mauss que habitus irá começar a ganhar destaque enquanto categoria sociológica e antropológica, à medida que Mauss (no ensaio sobre "As técnicas do corpo" de 1934) passara a analisar tal categoria enquanto fenômeno social que se altera de acordo com diversas variáveis (indivíduo, sociedade, educação, prestígio etc.) e elabora a razão prática coletiva e individual da sociedade.

Após Mauss, o conceito ressurgiu de forma proeminente na fenomenologia com o filósofo Edmund Husserl, para o qual habitus carregava a ideia de uma atitude mental situada entre experiências passadas e ações futuras. Husserl também utilizava o congênere conceitual "habitualitat", traduzido posteriormente por Alfred Schutz como "conhecimento habitual" (WACQUANT, 2007).

A teoria sociológica do século XX não se absteve de discutir tal categoria, e teve em dois grandes sociólogos o esforço intelectual desse trabalho: o alemão Nobert Elias e o francês Pierre Bourdieu. O exame e desenvolvimento da concepção de habitus a partir dessas duas tradições teóricas diferentes teve sua relevância na missão de trabalhar a análise do comportamento humano a partir da interação indivíduo e sociedade. Como menciona Dendasck e Lopes (2016, p. 02): 
Ambos os autores trabalham uma sociologia onde as estruturas sociais objetivas e subjetivas se encontram e se complementam, consequentemente se tem então o pressuposto de que o indivíduo não se isola deste processo, sendo que ele sofre fortes influências de seu contexto.

Apesar das distinções conceituais que cada um imprimiu em suas obras, a categoria habitus possui noções teóricas semelhantes que se conservam ao longo da história e dos teóricos que dela se apossam. A seguir poderá se observar as convergências e divergências da noção de habitus em Elias e Bourdieu.

\subsection{0 habitus em Nobert Elias}

Seguindo uma ordem cronológica, temos primeiro o sociólogo alemão Nobert Elias (1897-1990). O referido teórico nasceu na cidade de Breslau, na Polônia, sendo filho de família judaica, viveu na Alemanha e foi perseguido pelo nazismo o que o levou a exilar-se em 1933 na França. Antes de estudar Sociologia, estudou Medicina e Filosofia. Por ser proveniente de uma família de boas posses, ocupou um espaço social culto e elitizado que Ihe permitiu desde pequeno ter acesso aos clássicos da literatura humanista alemã e universal o que influenciou fortemente sua trajetória intelectual (SETTON, 2018).

Todavia, mesmo tendo escrito sua tese de habilitação aos 33 anos de idade, somente aos 57, já vivendo na Inglaterra, é que Elias ocupou um cargo de professor universitário na Universidade de Leicester, junto ao Departamento de Sociologia, trabalhando por lá durante dez anos, e escrevendo seu livro Introdução à Sociologia. Já com 65 anos passou um período de cerca de quatro anos como professor convidado da Universidade de Gana (SETTON, 2018).

Sua obra mais reconhecida foi o Processor Civilizador, publicada em 1939, porém, assim como outras obras de sua autoria ela só se tornou reconhecida décadas depois. Suas obras tiveram como enfoque principal a relação entre poder, comportamento, emoção e conhecimento na história (LANDINI, 2006).

Setton (2018, p. 05) ao referir-se a Nobert Elias afirma que:

Como caçador de mitos, metáfora expressiva que apresenta em seus escritos, conseguiu romper com algumas armadilhas de um pensamento sociológico rígido e acabou por legar um corpo conceitual capaz de apreender a dinâmica dos fenômenos sociais. Inquieto, corajoso e inovador, ele contribuiu para uma 
expressiva guinada na mentalidade do pensamento social contemporâneo. Nas palavras de Bourdieu, foi um heterodoxo.

Todavia, as circunstâncias históricas não foram favoráveis a difusão e reconhecimento do trabalho de Elias, que por conta disso permaneceu por um longo período como um autor marginal, voltando a ser estudado na década de 70 por uma nova geração de teóricos que souberam valorizar seu trabalho e the colocar entre os mais influentes sociólogos de todos os tempos (LANDINI, 2006).

Um ponto chave dentro do estudo teórico de Nobert Elias para se entender sua concepção de habitus é o conceito de configuração social. Neste sentido, o próprio autor afirma: "umas das questões centrais da sociologia, talvez a questão central, seja saber de que modo e por que os indivíduos estão ligados entre si, constituindo, assim, configurações dinâmicas específicas" (ELIAS, 2001, p. 213).

Areias e Marques (2012) ao tratarem sobre a sociologia configuracional de Elias relatam que o sociólogo resguarda a ideia de que a sociedade se constitui a partir das relações sociais formadas entre o "eu", o "tu", o "nós", o "eles" etc., ou seja, a sociedade se forma pela interelação de indivíduos diferentes, mas que se tornam iguais pela interdependência.

Nesse sentido, o exemplo do jogo empregado por Elias (1999) traz uma boa elucidação a respeito do que vem a ser configuração na concepção teórica do sociólogo. Veja:

Se quatro pessoas se sentarem à volta de uma mesa e jogarem cartas, formam uma configuração. As suas ações são interdependentes. Neste caso, ainda é possível curvarmo-nos perante a tradição e falarmos do jogo como se este tivesse uma existência própria. É possível dizer: "O jogo hoje à noite está muito lento!". Porém, apesar de todas as expressões que tendem a objetivá-lo, neste caso o decurso tomado pelo jogo será obviamente o resultado das ações de um grupo e indivíduos interdependentes. Mostrámos que o decurso do jogo é relativamente autónomo de cada um dos jogadores individuais, dado que todos os jogadores têm aproximadamente a mesma força. Mas este decurso não tem substância, não tem ser, não tem uma existência independente dos jogadores, como poderia ser sugerido pelo termo "jogo". Nem o jogo é uma ideia ou um "tipo ideal", construído por um observador sociológico através da consideração do comportamento individual de cada um dos jogadores, da abstraç̧ão das características particulares que os vários jogadores têm em comum e da dedução que destas se faz de um padrão regular de comportamento individual (ELIAS, 1999, p. 141-142). 
Pelo conceito de configuração, Nobert Elias atinge uma façanha dentro do pensamento sociológico do século $X X$, transpassando a oposição entre individuo e sociedade enquanto estruturas autônomas e independentes.

Ademais, o sociólogo, demonstra em sua teoria que os conceitos de "indivíduo" e "sociedade" também não são estáticos, haja vista estarem sempre sofrendo trasformações; e que apesar de se diferenciarem, tais conceitos também fazem parte de uma mesma estrutura. Com isso, possibilita-se que haja a análise da formação dos sujeitos a partir de outros referenciais, como o lugar social que eles ocupam, das relações com suas normas e regras, e do processo de internalização e constragimento das pulsões e emoções de cada um (ELIAS, 2001).

Desta configuração social, que conforme o sociólogo age de forma a moldar os indivíduos e cria padrões dentro da relação de interdependência entre o indivíduo e a sociedade (ELIAS, 1999) é que surge o habitus. Ademais, mesmo que esta categoria seja secundária e não sujeita a um certo refinamento e sistematização na obra de Elias, como aponta Setton (2013), têm-se que perceber seu esforço e importância teórica.

Dessa forma, para Elias (1994), o comportamento humano teria em certa medida uma composição compartilhada, mesmo que haja individualidades em cada pessoa. Esse espaço comum do comportamento humano seria o habitus. Nas palavras do autor (ELIAS, 1994, p. 150):

\begin{abstract}
Cada pessoa singular, por mais diferente que seja de todas as demais, tem uma composição específica que compartilha com os outros membros de sua sociedade. Esse habitus, a composição social dos indivíduos, como que constitui o solo de que brotam as características pessoais, mediante as quais um individuo difere dos outros membros de sua sociedade. Dessa maneira, alguma coisa brota da linguagem comum que o individuo compartilha com os outros e que é, certamente, um componente do habitus social, um estilo mais ou menos individual, algo que poderia ser chamado de grafia individual inconfundível que brota da escrita social.
\end{abstract}

Há de se sublinhar ainda que, em obras como A Sociedade da Corte (2001) e A Sociedade dos Indivíduos, Elias explora o advento do habitus nos contextos da sociedade moderna e contemporânea, bem como das cortes europeias.

Conforme Dendasck e Lopes (2016), esta investigação de Elias sobre o habitus já iniciara em sua primeira obra, O Processo Civilizador, onde o sociólogo pesquisou a 
ontologia das expressões civilização e cultura para demonstrar que, através do imperialismo europeu, o modelo de vida deste continente passou a ser imposto sobre o próprio habitus dos indivíduos.

Em síntese, temos na sociologia configuracional de Elias uma categoria de habitus que se apresenta de maneira complexa e que se estrutura historicamente em redes intercomunicantes formando padrões comportamentais. Ademais, há de se verificar que o habitus em Elias é fruto de uma tensão, à medida que é condicionado pela estrutura e ao mesmo tempo autônomo em relação a ela.

\subsection{O habitus em Pierre Bourdieu}

Em seguida, temos o sociólogo francês Pierre Felix Bourdieu, nascido em Déguin em uma cidade interiorana no sudoeste da França no ano de 1930, morreu em 2002 em Paris aos 72 anos de idade. De família com origem simples e provinciana Bourdieu saiu do campo e foi para as grandes cidades da França estudar, conseguindo atingir uma carreira acadêmica notável.

Conforme Setton (2018), Bourdieu como muitos de seus contemporâneos se tornou um autodidata na Sociologia e na Antropologia. Apesar de uma origem interiorana frequentou as melhores instituições de ensino da França e se licenciou em filosofia na École Normale Supérieure em 1954. No ano seguinte partiu para a Argélia, retornando a França somente em 1961 quando passou a lecionar na Universidade de Lille. Nos anos seguintes passou por diversas instituições e tornou-se bem reconhecido no meio acadêmico.

Bourdieu sempre trabalhou em equipe, e com isso conseguiu estabelecer sua própria escola de sociologia, apesar de ser filosofo de formação. Lançou numerosos trabalhos ao longo de sua carreira, abordando temas como dominação, educação, cultura, literatura, arte, mídia, política, linguística entre outros temas, tornando-se um dos autores mais lidos em todo o mundo nas áreas da antropologia e da sociologia (MORAES, 2007).

Vasconcellos (2002), ao expor sobre a vida de Bourdieu, menciona que o teórico conseguiu de modo eficaz aliar seu engajamento político ao seu trabalho intelectual. Ademais, a experiência que Bourdieu teve, de ter ido prestar serviço militar obrigatório 
logo após ter se graduado lhe rendeu a escrita de suas primeiras obras, iniciando a investigação sobre uma das categorias mais relevantes de sua obra: o habitus.

Em Bourdieu, para se falar de habitus é necessário mencionar antes outra categoria, qual seja, a de campos, pois os dois conceitos estão interligados. Nas palavras do sociólogo, os campos seriam "microcosmos relativamente autônomos" com determinadas leis e regras, a qual estaria situado em um espaço social mais amplo (BOURDIEU, 2004, p. 18).

Há uma diversidade de tipos de campos, "campos literário, artístico, jurídico ou científico, isto é, o universo no qual estão inseridos os agentes e as instituições que produzem, reproduzem ou difundem a arte, a literatura ou a ciência. Esse universo é um mundo social como os outros, mas obedece a leis próprias" (BOURDIEU, 2004: 20).

Souza (2014) menciona o exemplo da Academia enquanto campo, esta depende de um macrocosmo e se submete a leis sociais próprias como os diversos campos, mas por outro lado, também possui uma lógica interna própria, que só é entendida por quem está dentro do campo e possui o habitus desse campo. No mesmo sentido, o próprio Bourdieu (1996, p. 141) adverte: "cada campo impõe um preço de entrada tácito".

Tentando explicar de maneira mais simples, Constantino e Neto (2014) exprimem, a grosso modo, os campos como espaços sociais diferenciados, possuidores de estrutura própria e de relativa autonomia em relação aos demais campos. Outrossim, sua reprodução acompanha uma lógica interna de um habitus específico que tende a permanecer. Assim, pode-se entender cada campo como um locus onde padrões de comportamentos, em grande parte das vezes inconscientes, conformam-se e geram habitus próprios.

Como alertam ainda Araújo et al. (2009), não se deve esquecer que os campos são espaços onde também ocorrem disputas de poder, haja vista que se formam por sujeitos dominantes e dominados que concorrem entre si por maior reconhecimento e pela obtenção de capital.

A conexão entre os conceitos de campos e habitus, fica ainda mais clara quando vemos do que exatamente trata esta categoria na perspectiva de Bourdieu. 
Habitus são princípios geradores de práticas distintas e distintivas - o que o operário come, e sobretudo sua maneira de comer, o esporte que pratica e sua maneira de praticá-lo, suas opiniões políticas e sua maneira de expressá-las diferem sistematicamente do consumo ou das atividades correspondentes ao do empresário industrial; mas são também esquemas classificatórios, princípios de classificação, princípios de visão e de divisão e gostos diferentes. Eles estabelecem a diferença entre o que é o bom ou é mau, entre o bem e o mal, entre o que é distinto e o que é vulgar, etc., mas elas não são as mesmas. Assim, por exemplo, o mesmo comportamento ou o mesmo bem pode parecer distinto para um, pretensioso ou ostentatório para ouro e vulgar para um terceiro (BOURDIEU, 1996, p. 22).

Assim para o sociólogo francês, o habitus está ligado diretamente ao campo em que o sujeito ocupa. Pode-se dizer então, que o comportamento humano nessa perspectiva é moldado em grande parte pelo campo, e consequentemente pelo habitus ali praticado, já que este último é uma "estrutura estruturada predisposta a funcionar como uma estrutura estruturante" (BOURDIEU, 2009, p. 87).

Segundo Setton (2002), na perspectiva bourdiesiana, o habitus pode ser então entendido como um conjunto de esquemas individuais construídos coletivamente, ou seja, ele existe através de disposições estruturadas no campo social, e disposições estruturantes constituídas na mente de cada um, por meio de experiências anteriores e que também adquirem um caráter simbólico. Desse modo, ao observar a relação entre indivíduo e sociedade pela ótica do habitus, há se notar que o individual e o social se constituem de forma simultânea, estando os dois ligados de modo profundo e se influenciando a todo o momento.

Martinez e Campos (2015) ainda mencionam que por conta dessa característica do habitus em Bourdieu, que relaciona experiências passadas com condições do presente, temos a constituição de um certo padrão de ações que se reproduz no futuro, seja através da formação de gostos pessoais, ou do modo de vestir, pensar ou sentir. Assim, o habitus se integra nas práticas dos indivíduos à medida que é moldado historicamente.

Posto as noções de habitus nos dois sociólogos, percebe-se algumas diferenças entre as concepções de cada um, principalmente quanto aos conceitos correlatos utilizados por cada teórico que dão embasamento a explicação dessa categoria. Em Elias temos de entender a configuração social para chegar ao contexto em que se insere o 
habitus em sua teoria. Já em Bourdieu, é imprescindível ter em mente sempre a ideia de campo relacionada ao habitus.

Todavia, apesar das distâncias teóricas em que a categoria habitus percorre nos dois autores, têm se resguardado uma semelhança que vem desde a origem do termo. Tanto em Elias como em Bourdieu há uma semelhança na concepção de habitus enquanto constituinte de um padrão comportamental. Assim, é nesse sentido que se buscará discutir a seguir a formação de um certo padrão comportamental no campo jurídico, um verdadeiro habitus que pinguiniza, sujeitos que adentram o campo forense.

\section{A FORMAÇÃO DE UM HABITUS JURÍDICO PINGUINIZADO}

A priori, cumpre mencionar que somente Bourdieu aventurou-se a abordar em seus estudos o habitus jurídico, e consequentemente o seu campo. Elias não ousou aventurarse nesta área, muito menos desenvolveu de forma mais profunda esta categoria, como Bourdieu. Todavia, a semelhança entre as noções de habitus entre os dois autores permite uma análise do habitus jurídico, levando em conta a possibilidade de caracterização de um determinado padrão comportamental dos indivíduos que ocupam esses espaços.

Segundo a definição de Bourdieu (1989, p. 212), o campo jurídico seria:

O lugar de concorrência pelo monopólio do direito de dizer o direito, quer dizer, a boa distribuição ou a boa ordem, na qual se defrontam agentes investidos de competência ao mesmo tempo social e técnica que consiste essencialmente na capacidade reconhecida de interpretar (de maneira mais ou menos livre ou autorizada) um corpus de textos que consagram a visão legitima, justa, do mundo social.

Assim, o campo jurídico é tido como um espaço social formado pelas instituições, pelas normas e pelos especialistas, aqueles autorizados a interpretar e aplicar o direito, isto é, conforme Bourdieu (1989), dizer a medida certa do direito de forma justa, conforme o habitus do próprio campo jurídico.

A constituição desse campo jurídico implica necessariamente na existência de todo um sistema que organiza e hierarquiza não só o enorme corpo técnico implicado na produção, interpretação e aplicação do direito, mas também as outras instituições envolvidas e sua relação com os demais campos sociais. Toda esta estrutura preocupada 
em manter-se legitima, além de criar uma suposta aparência de neutralidade e autonomia, requer ainda a construção de um forte habitus, que seja bastante específico (CONSTANTINO; NETO, 2014).

Nesse sentido, Bourdieu (1989) observa que as práticas e discursos desses campos são consequências de uma lógica específica duplamente determinada, o que dá espaço a constituição e desenvolvimento de um habitus próprio deste campo. Conforme o autor (BOURDIEU, 1989, p. 211):

\begin{abstract}
As práticas e os discursos jurídicos são, com efeito, produto do funcionamento de um campo cuja lógica específica está duplamente determinada: por um lado, pelas relações de força específicas que the conferem a sua estrutura e que orientam as lutas de concorrência ou, mais precisamente, os conflitos de competência que nele têm lugar e, por outro lado, pela lógica interna das obras jurídicas que delimitam em cada momento o espaço dos possíveis e, deste modo, o universo das soluções propriamente jurídicas.
\end{abstract}

Ademais, há de se perceber também, que a constituição desse habitus específico do campo forense, se apresenta como relação de poder sobre os outros campos, não tendo apenas um acaso que afastou a visão jurídica das demais visões de outros campos. Desse modo Bourdieu (1989, p. 226) justifica que:

O desvio entre a visão vulgar daquele que se vai tornar num "justificável", quer dizer, num cliente, e a visão cientifica do perito, juiz, advogado, conselheiro jurídico etc., nada tem de acidental; ele é constitutivo de uma relação de poder, que fundamenta dois sistemas diferentes de pressupostos, de intenções expressivas, numa palavra, duas visões de mundo.

Porém, é necessário sublinhar que a simples entrada de um sujeito no campo jurídico não leva a interiorização do habitus jurídico. Como aponta Constantino e Neto (2014) a inculcação progressiva dos padrões do campo forense requer a passagem do neófito por inúmeros rituais de iniciação.

Taves (2012) aponta que a formação deste habitus em muitos casos não começa apenas com o ingresso na faculdade de direito, mas muitas das vezes já inclui um trajeto que liga a vida do aspirante a jurista a trajetória de vida de familiares que já ingressaram na carreira jurídica.

Porém, talvez o aspecto que contribui mais fortemente para a formação desse habitus específico, e em certa medida pinguinizado - conforme a concepção waratiana - é 
o modo como se apresenta e se constitui a maioria dos cursos de direitos, especialmente, no Brasil, em que o curso desde o princípio foi destinado a elites para ocupar os postos de comando do Poder Judiciário e de outros lugares de exercício do poder estatal.

No âmbito acadêmico do direito, os diversos cursos pelo Brasil dão primazia a uma formação prática, investindo em disciplinas de eixo profissionalizante e deixam de lado disciplinas de eixo fundamental, como a filosofia, a sociologia, a antropologia etc. Além disso, o predomínio do formalismo e metodologias de ensino que privilegiam aulas exaustivas de análise de leis e jurisprudências, apoiadas em manuais esquematizados e longe de qualquer contato com uma reflexão social, tornam-se o caminho para interiorização de um habitus jurídico defasado e apático à realidade social (CONSTANTINO; NETO, 2014).

Ademais, o modo como à educação jurídica se apresenta e ajuda a formar o habitus do campo forense, consoante Faleiros e Gallupo (2009), condena estudantes e professores a um estado de reféns de uma estrutura fracassada e longe de entender e reproduzir o real objetivo do Direito, como o que é responsável pela pacificação dos conflitos que ao Poder Judiciário são conduzidos.

Nesse sentido, se mostra oportuno o pensamento do jurista argentino Luis Alberto Warat, que mesmo não tendo trabalhado com a categoria habitus, observou em certa medida padrões comportamentais contidos no campo jurídico e sua prática, fomentados principalmente pelo ensino jurídico liberal-tradicional.

Ao se referir a esse ensino jurídico Warat (1997) critica sua abordagem fantasiosa que se cega diante de razões já consumidas pela história e que não tem mais sentido diante das práticas pedagógicas atuais:

\footnotetext{
Como mortos que falam da vida, o saber tradicional do direito mostra suas fantasias perfeitas na cumplicidade cega de uma linguagem sem ousadias, enganosamente cristalina, que escamoteia a presença subterrânea de uma "tecnologia da alienação". Utopias fantasiadas de si mesmas que explicam com razões consumidas pela história, novas formas de legitimação das práticas ilícitas do Estado (WARAT, 1997, p. 42).
}

A analogia da pinguinização do direito mencionada por Warat em suas aulas no curso de direito, se encaixa bem nesse contexto, à medida que os vários mecanismos do 
campo jurídico criam um habitus que moldam pinguins, vestidos de branco e preto, insensíveis e fechados.

Como mencionado por Lopes (2014) a partir de uma visão waratiana, a formação dos estudantes de direito é o ponto inicial de um processo de pinguinização, ou seja, de um modo em que todos agem da mesma forma e reproduzem padrões dogmaticamente estabelecidos, em que nada tem de novo ou de científico.

No mesmo sentido Tokarsi (2009), ao explorar a temática posposta por Warat, que denominou a metodologia adotada pelas ciências jurídicas como uma pinguinização dos bacharéis de Direito, conceitua tal processo como a

perda da sensibilidade dos estudantes de Direito na medida em que os mesmos vão sendo submetidos a uma (de)formação baseada em um pensamento uniforme e alienante sobre o Direito. Seus corpos também correspondem a esse processo (TOKARSI, 2009, p. 23).

Rocha (2012) explica que Warat utilizou a alegoria do "pinguim" para referir-se de modo criativo e bem humorado da transformação pela qual todo o estudante de Direito passaria no decorrer do curso, homogeneizando indivíduos, colocando-os sem desejo e vontade, e até mesmo padronizando-os esteticamente. Mas sobretudo, a pinguinização mencionada por Warat transformava os sujeitos em conformistas comprometidos com os valores do grupo dominante.

Warat não refletiu propriamente sobre a categoria do habitus, como no caso de Elias e Bourdieu. Porém, seu diagnóstico e crítica ao mundo jurídico (ou nas palavras de Bourdieu, ao campo jurídico), especialmente ao ensino jurídico, possibilita que um esforço teórico nos leve a relacionar a formação de um habitus jurídico ao processo de pinguinização exposto por este jurista, que leva a padronização de uma prática jurídica em descompasso com a realidade social, principalmente, porque se mostra apática e insensível a outros campos da sociedade.

\section{DESCONSTRUINDO O HABITUS JURIDICO PINGUINIZADO PELA "FOLIA": A PROPOSTA PEDAGÓGICA DE LUIS ALBERTO WARAT}

Após um diagnóstico que revelou a partir dos trabalhos desenvolvidos por Pierre Bourdieu e Nobert Elias que certas práticas tendem a ser reproduzidas em campos sociais 
distintos, e que no caso do campo jurídico, isso não é diferente, pois há um habitus que molda sujeitos a buscarem o monopólio de dizer o direito (BOURDIEU, 1989). Pode-se enxergar nos estudos e indagações de Warat certa semelhança com o trabalho de ambos os sociólogos, especialmente, como mencionado anteriormente, se comparar o processo de reprodução do habitus ao processo de pinguinização.

A pinguinização que molda práticas jurídicas comuns nos diferentes sujeitos pertencentes ao espaço forense e retira qualquer sensibilidade através de seus próprios mecanismos de reprodução (TOKARSI, 2009), em muito tem relação com o habitus, à medida que ambos formam certos padrões de práticas reproduzidas dentro de campos determinados e que por isso mesmo, caracterizam estes espaços.

Todavia, esse habitus pinguinizado que transforma operadores do direito em máquinas estáticas de terno e gravata comprometidas com valores distantes da realidade social, prejudica sobremaneira a aplicação do direito sobre os seres humanos, isso por que como adverte Faleiros e Maciel (2015), o Direito é uma ciência em movimento, e por conta disso requer de seus preceitos e práticas reflexões constantes, ainda mais porque o seu alvo que é a sociedade, é dinâmica.

De modo a enfrentar essa conjuntura, Warat se aventurou em grande parte de sua vida a propor um ensino que vá além do raciocínio lógico-dedutivo da norma e dos métodos interpretativos exegéticos, permitindo ao estudante do curso de direito desconstruir essa ordem simbólica e reformular o imaginário instituído (WARAT, 1988).

Reagindo a concepção kelseniana que influência claramente a pedagogia liberaltradicional, Warat (1997) observa que a manutenção do modelo de ensino atual, seria o mesmo que manter os estudantes

[...] prisioneiros de uma censura que não poderá ser abalada por nenhuma prática de autonomia. O fenômeno da alienação chegará a seu fim em formas de sociedade que façam a experiência da informação fora dos corpos, separando o sentido dos homens (WARAT, 1997, p.60).

Para Warat (1997), o professor de direito tem um importante papel nessa intervenção contra a pedagogia liberal-tradicional. Para exercer de forma correta suas funções deve reagir a este modelo de educação defasado por meio de uma pedagogia da 
dignidade e da solidariedade social. Nesse projeto de ensino, diz Warat: "a luta pela dignidade começa na tentativa de desembaraçar o discurso docente das suas vestes sacerdotais e da competência de suas provocações" (WARAT, 1997, p. 63).

Ademais, Warat (1985) propõe transformar o espaço acadêmico em um local mais leve, já que para ele este não é um local de submissão ou repetição de discursos, mas sim um local de cumplicidade entre professor e aluno. Nessa lógica ele, enquanto professor, chega a se vê como

[...] um mágico, um ilusionista, um vendedor de sonhos, de ilusões e fantasias. Quando eu entro numa sala de aula proponho, imediatamente, a substituição do giz por uma cartola. Dela sairão mil verdades transformadas em borboletas... com meu comportamento docente, procuro a utopia, falsifico a possibilidade de produção de um mundo, de/e pelo desejo. Ministro sempre uma lição de amor, provoco e teatralizo um território de carências. Quando invado uma sala de aula se amalgamam ludicamente todas as ausências afetivas. De diferentes maneiras, sempre me preocupo em expor a crítica à vontade de verdade, partir da vontade do desejo, como bom alquimista que sou, transformo o espaço de uma sala de aula em um circo mágico. Assim é que executo a função da pedagogia da loucura (WARAT, 1985, p. 152-153).

Afinal de contas, transformar as práticas desses espaços se torna necessário quando têm-se em mente que a ação de ensinar é um prática violenta. Para o jurista, "ensinar é impor, é invadir, doutrinar, disciplinar, controlar, desumanizar. Ensinar é formar um homem unidimensional" (WARAT, 2004, p. 425). O professor que segue os moldes de ensino jurídico tradicional, segundo Warat (2004) simula a escolarização, em vez da humanização.

Para que se desconstrua esse habitus jurídico piguinizado é necessário bastante esforço. Todavia, no caso específico do ensino jurídico, uma saída apontada por Warat para esse problema seria sua carnavalização. Como aponta o autor (WARAT, 1985, p. 133):

Ao carnavalizar a aula, ter-se-á a esmagadora sensação de estar presente na vida. Sairemos dela leves. Teremos espantado os lugares pré-montados e negado a palavra autoritária. A didática carnavalizada é uma excelente possibilidade para destruir a relação mestre-discípulo. 0 mestre fora do lugar é a grande atitude carnavalizadora do ensino. Num contexto de ensino carnavalizado, o lugar do discipulado não é mais o lugar do outro. Seu lugar é sua práxis.

A ideia de carnavalização empregada por Warat foi apossada a partir da obra do filósofo russo Mikhail Bakhtin. O referido autor verificou a importância do carnaval 
enquanto instante de libertação em relação a todo um sistema de relações desiguais e opressoras que constantemente confrontam os indivíduos. Ademais, momentos em que é possível inverter o lugar de pertencimento do mundo, sentir prazer e debochar da ordem, o carnaval é um ato libertador para qualquer sujeito que se encontre em uma posição subalternizada (BAKHTIN, 1999).

Nas palavras do próprio Bakhtin (1999, p. 18):

O carnaval ignora toda a distinção entre atores e espectadores [...] Os espectadores não assistem ao carnaval, eles o vivem, uma vez que o carnaval pela sua própria natureza existe para todo o povo. Enquanto dura o carnaval, não se conhece outra vida senão o carnaval [...] Durante a realização da festa só se pode viver de acordo com suas leis, isto é, as leis da liberdade. O carnaval possui um caráter universal, é um estado peculiar de mundo: o seu renascimento e a sua renovação, dos quais participa cada indivíduo. Essa é a própria essência do carnaval, e os que participam dos festejos sentem-no profundamente.

Warat bebe diretamente dessa fonte para pensar a carnavalização de suas aulas e buscar uma pedagogia que deboche das propostas colocadas ao ensino jurídico e suas práticas reproduzidas por seus alunos. A "folia" da carnavalização da aula, assim, segundo Warat (1997) permitiria a criação de um espaço de criatividade, de rompimento com o arcaico, de espontaneidade e de recepção do novo. Por isso, "a carnavalidade procura sempre o tom fragmentado para desfazer as representações ideológicas, para fazer explodir as avessas a microfísica dos segredos que sustentam as ordens totalitárias das verdades" (WARAT, 1988, p. 71).

Nessa perspectiva de desconstrução de um habitus jurídico pinguinizado, a carnavalização do ensino jurídico seria, portanto, buscar promover outras significações e articulações entre as práticas que moldam o operador do direito. 0 imaginário carnavalizado pensado por Warat (1985) teria, portanto, o condão de organizar as significações do habitus jurídico

[...] à margem da pertinência que os códigos consagram, vale dizer, das homogeneidades que fazem os sentidos de uma língua: sentidos que não são inteiros aos códigos, mas sem que suas ambiguidades constitutivas atinjam o nível intolerável. Estou falando de um imaginário produtor e não consumista, privilegiando a instância de produção de reconhecimento das significações. Isto é: empregando uma gramática de reconhecimento dos sentidos que sempre the acrescentam um "plus" de significação ao reconhecê-los. Solicita-se dessa maneira, uma prática social permanente produtora de suplementos de 
significações. Na univocidade dos sentidos o homem não encontra nunca uma visão crítica da sociedade (WARAT, 1985, p. 98).

Portanto, nesse viés, a carnavalização do ensino jurídico se mostra como uma proposta surrealista do ensino universitário, que por sua concepção pode ter a capacidade de modificar o habitus jurídico que pinguiniza, adestra, domina e castra os jovens operadores do direito. Como pondera Warat (1985), a carnavalização do ensino jurídico tem necessidade de emergir justamente porque há de se criar novos desejos que emancipem a cultura jurídica do maniqueísmo juridicista.

\section{CONSIDERAÇÕES FINAIS}

A sociologia, como já apontara Giddens (2009), por sua própria natureza está sujeita a polemizar as mais diversas questões. Tal característica permite aos pesquisadores movimentarem-se com certo conforto pelos mais variados temas e áreas, como no caso deste ensaio. Ademais, atualmente, não só os clássicos como Durkheim, Weber ou Marx tem a possibilidade de subsidiar pesquisas com suas ideias. $\mathrm{O}$ pensamento sociológico contemporâneo possui um arcabouço de autores que desenvolveram teorias vigorosas que também tem energia para subsidiar novos estudos.

Dentre os tantos teóricos da sociologia contemporânea, este trabalho utilizou-se de dois: Nobert Elias e Pierre Bourdieu. Ambos foram tratados aqui em virtude do desenvolvimento de uma categoria específica para a sociologia: o habitus. Apesar da noção de habitus ter suas semelhanças nos trabalhos dos dois, exprimindo as ações que se reproduzem no tempo e no espaço em determinados locais, Bourdieu e Elias divergem principalmente quanto aos conceitos correlatos que fundamentam a ideia de habitus em cada um.

Todavia, o importante aqui para as discussões realizadas fora perceber que no campo do Direito há a constituição de um habitus específico, que molda e dá caracteres ao espaço forense e consequentemente aos indivíduos que a ele pertencem. O próprio Bourdieu (1989) em seus estudos se aventurou a analisar e caracterizar o habitus jurídico.

Em certa medida o diagnóstico desse habitus presente no campo jurídico revela um problema na práxis dos operadores do Direito, à medida que se correlaciona a perspectiva 
de habitus presente no pensamento de Elias e Bourdieu, com as ideias de Warat, principalmente no que concerne ao processo de pinguinização que acomete os sujeitos que adentram o campo jurídico.

Ao analisar o processo de pinguinização com o auxílio da categoria sociológica do habitus, há de se perceber que as práticas reproduzidas no interior do campo jurídico tendem a transformar operadores do direito em máquinas estáticas de terno e gravata, comprometidos com valores distantes da realidade social, e acomodados na ordem dominante.

A saída apresentada aqui para se começar a repensar essas práticas constantemente reproduzidas no campo forense e que criam juristas "pinguins" é a intervenção no ensino jurídico, como aposta Warat, por meio da carnavalização. Embasado na ideia de carnavalização do filosofo Bakhtin, Warat (1985) acredita que a ideia libertadora do carnaval empregada em sala de aula pode desfazer as representações ideológicas e explodir as avessas as ordens totalitárias do espaço de ensino jurídico, o que em grande medida acreditamos poder contribuir para desconstruir o habitus pinguinizado do Direito, dando espaço a uma nova prática desse sistema.

\section{REFERÊNCIAS}

ALTMANN, Eliska. Tipificação, habitus e interdependência: emblemas para um debate sociológico. Ciências Sociais Unisinos, v. 41, n. 3, p. 143-150, 2005.

ARAUJO, Flávia Monteiro de; ALVES, Elaine Moreira; CRUZ, Monalise Pinto da. Algumas Reflexões em torno dos conceitos de Campo e Habitus na obra de Pierre Bourdieu. Revista Perspectivas da Ciências e Tecnologia, v. 1, n. 1, p. 31-40, 2009.

AREAIS, Helena; MARQUES, Ana Paula. Redes e reconfiguração organizacional: o contributo de Norbert Elias. Configurações, n. 9, p. 37-56, 2012.

BAKHTIN, Mikhail. Marxismo e filosofia da linguagem. 9. ed. São Paulo: Hucitec, 1999.

BOURDIEU, Pierre. O poder simbólico. Lisboa: Difel, 1989.

BOURDIEU, Pierre. O senso prático. Petropólis: Editora Vozes, 2009.

BOURDIEU, Pierre. Os usos sociais da ciência: por uma sociologia clínica do campo científico. São Paulo: Editora UNESP, 2004. 
BOURDIEU, Pierre. Razões Práticas: Sobre a teoria da ação. Campinas: Papirus Editora, 1996.

CASANOVA, José Luís. Uma avaliação conceptual do habitus. Sociologia - Problemas e práticas, Lisboa, n. 18, 1995.

CONSTANTINO, Alexandre Krügner; NETO, Francisco Raimundo Alves. O Campo Jurídico e a Pesquisa em Direito no Brasil: Uma Problematização sob a Perspectiva Teórica de Pierre Bourdieu. In: CONGRESSO NACIONAL DO CONPEDI, 23., 2014, Florianópolis. Anais [...]. Florianópolis: CONPEDI, 2014.

DENDASCK, Carla Viana; LOPES, Gileade Ferreira. Conceito de Habitus em Pierre Bourdieu e Norbert Elias. Revista Científica Multidisciplinar Núcleo do conhecimento, v. 3, ano 1, p. 1-10, maio 2016.

DUBAR, Claude. A socialização: Construção das identidades sociais e profissionais. São Paulo: Martins Fontes, 2005.

ELIAS, Norbert. A Sociedade da Corte: Investigação sobre a sociologia da realeza e da aristocracia de corte. Rio de Janeiro: Jorge Zahar Editor, 2001.

ELIAS, Norbert. A Sociedade dos Indivíduos. Rio de Janeiro: Editora Jorge Zahar, 1994.

ELIAS, Norbert. Introdução à Sociologia. Lisboa, Edições 70, 1999.

ELIAS, Norbert. O Processo Civilizador. 2. ed. Rio de Janeiro: Editora Jorge Zahar, 1994.

FALEIROS, Thaisa Haber; GALLUPO, Marcelo Campos. A formação do docente de direito: uma identidade desejada. In: CONGRESSO NACIONAL DO CONPEDI, 8., 2009, Zaragoza. Anais [...]. Zaragoza: CONPEDI, 2009.

GIDDENS, Anthony. A constituição da sociedade. 3. ed. São Paulo: Martins Fontes, 2009.

LANDINI, Tatiana Savoia. A Sociologia de Norbert Elias. BIB, n. 61, p. 91-108, 2006.

LOPES, Jorge Antonio Paes. Entre pavões e pinguins: a questão da metodologia e da pesquisa em Direito. Revista Jus Navigandi, Teresina, ano 19, n. 3907, 13 mar. 2014. Disponível em: https://jus.com.br/artigos/26881. Acesso em: 29 dez. 2018.

MARTINEZ, Flavia Wegrzyn; CAMPOS, Jeferson de. A Sociologia de Pierre Bourdieu. Revista Eletrônica da FEATI, n. 11, 2015.

MORAES, Ulisses Quadros de. Pierre Bourdieu: campo, habitus e capital simbólico um método de análise para as políticas públicas para a música popular e a produção musical em Curitiba (1971-1983). In: FÓRUM DE PESQUISA CIENTIFICA EM ARTE, 5., 2007, [s. I.]. Anais [...]. [s.l.]: [s.n.], 2007. p. 180-192.

ROCHA, Leonel Severo. A aula mágica de Luis Alberto Warat. In: STRECK, Lenio Luiz; ROCHA, Leonel Severo; ENGELMANN, Wilson. Constituição, sistemas sociais e hermenêutica: anuário do programa de pós-graduação em Direito da Unisinos. Porto Alegre: Livraria do Advogado Editora/São Leopoldo: Unisinos, 2012.

SETTON, Maria da Graça Jacintho. A teoria do habitus em Pierre Bourdieu: uma leitura contemporânea. Revista Brasileira de Educação, n. 20, p. 60-70, 2002. 
SETTON, Maria da Graça Jacintho. Marcel Mauss e Norbert Elias: notas para uma aproximação epistemológica. Educação e Sociedade, Campinas, v. 34, p. 195-210, jan./mar. 2013.

SETTON, Maria da Graça Jacintho. Socialização de habitus: um diálogo entre Norbert Elias e Pierre Bourdieu. Rev. Bras. Educ., Rio de Janeiro, v. 23, e230072, 2018 . Disponível em http://www.scielo.br/scielo.php?script=sci_arttext\&pid=S1413-24782018000100602\&Ing =pt\&nrm=iso. Acesso em: 03 dez. 2018.

SOUZA, Rafael Benedito de. Formas de Pensar a Sociedade: O Conceito de Habitus, Campos e Violência Simbólica em Bourdieu. Revista Ars Historica, n. 7, jan./jun. 2014.

TAVES, Robert Steven Viera. Autonomia relativa do Direito em Pierre Bourdieu e o Normativismo: da Critica Sociológica à lógica própria do Direito. Revista Fac. Dir. Sul de Minas, Pouso Alegre, v. 28, n.1, p. 153-188, jan./jul. 2012.

TOKARSKI, Carolina Pereira. Com quem dialogam os bacharéis em direito da universidade de Brasília? A experiência da extensão jurídica popular no aprendizado da democracia. 2009. Dissertação (Mestrado em Direito, Estado e Constituição)-Coordenação de PósGraduação em Direito da Universidade de Brasília, Distrito Federal, 2009. Disponível em: http://repositorio.unb.br/bitstream/10482/7014/1/2009_CarolinaPereiraTokarski.pdf.

Acesso em: 29 dez. 2018.

VASCONCELLOS, Maria Drosila. Pierre Bourdieu: a herança sociológica. Educação \& Sociedade, n. 78, p. 77-87, 2002.

WACQUANT, Loic. Esclarecer o Habitus. Educação e Linguagem, ano 10, n. 16, p. 63-71, jul./dez. 2007. Disponivel em: https://www.metodista.br/revistas/revistasims/index.php/EL/article/viewFile/126/136. Acesso em: 27 nov. 2018.

WARAT, Luís Alberto. A ciência jurídica e seus dois maridos. 2. ed. Santa Cruz do Sul: EDUNISC, 1985.

WARAT, Luís Alberto. Introdução geral ao direito. O direito não estudado pela teoria jurídica moderna. Porto Alegre: Safe, 1997.

WARAT, Luís Alberto. Manifesto do surrealismo jurídico. São Paulo: Acadêmica, 1988.

WARAT, Luís Alberto. Surfando na pororoca. O oficio do mediador. Florianopólis: Boiteux, 2004.

SOUSA, Maria Sueli Rodrigues de; COSTA, Pablo

Cavalcante. A carnavalização do ensino jurídico como

fuga de um habitus pinguinizado. RBSD - Revista

Brasileira de Sociologia do Direito, v. 8, n. 1, p. 123-142,

jan./abr. 2021.

Recebido em: $16 / 04 / 2020$

Aprovado em: 17/09/2020 